\section{Commentary: Paraesophageal hernia repair: Don't slip up}

\author{
Nidhi Desai, MD, and Thomas Ng, MD
}

Repair of paraesophageal hernia has evolved greatly since its earliest description in 1919. ${ }^{1}$ Open thoracic approaches have made way to minimally invasive techniques by laparoscopy; however, recurrence rates have been high, reportedly up to $60 \% .^{2}$ Although most recurrences are radiographic, with rates of revision surgery being much lower, this high rate indicates that the surgical community still needs to improve.

The current Video Atlas article provided to us by Alicuben and colleagues ${ }^{3}$ is a detailed description of the operative technique used at the University of Pittsburgh Medical Center to achieve a successful and durable repair of paraesophageal hernias. The components of the repair need not be restated here, as they are clearly explained and demonstrated by the authors. Needless to say, each of these components are of vital importance to the repair and should be meticulously performed, without short cuts or compromise.

The surgeons at the University of Pittsburgh Medical Center have long been leaders in the field of minimally invasive foregut surgery. Luketich and colleagues ${ }^{4}$ had previously published their results of giant paraesophageal hernia repair by laparoscopy, reporting a radiographic recurrence rate of $15.7 \%$ and a reoperative rate for recurrence of $3.2 \%$. These results are comparable with the often-quoted benchmark set by Maziak and colleagues ${ }^{5}$ at the University of Toronto of $2.2 \%$ with transthoracic repair.

It is unlikely that the "Holy Grail" of zero recurrence after paraoesophageal hernia repair will ever be attained; the hiatus is a dynamic region under constant stress and strain, but the recurrence rates still appear to be high. It is imperative to show the medical community that we can

\footnotetext{
From the Division of Thoracic Surgery, University of Tennessee Health Science Center, College of Medicine, Memphis, Tenn.

Disclosures: The authors reported no conflicts of interest.

The Journal policy requires editors and reviewers to disclose conflicts of interest and to decline handling or reviewing manuscripts for which they may have a conflict of interest. The editors and reviewers of this article have no conflicts of interest.

Received for publication Aug 22, 2021; revisions received Aug 22, 2021; accepted for publication Aug 26, 2021; available ahead of print Sept 8, 2021.

Address for reprints: Thomas Ng, MD, 6025 Walnut Grove Rd, Suite 301, Memphis, TN 38120 (E-mail: tng4@uthsc.edu).

JTCVS Techniques 2021;10:507

2666-2507

Copyright (c) 2021 The Author(s). Published by Elsevier Inc. on behalf of The American Association for Thoracic Surgery. This is an open access article under the CC BY-NC-ND license (http://creativecommons.org/licenses/by-nc-nd/4.0/).

https://doi.org/10.1016/j.xjtc.2021.08.043
}

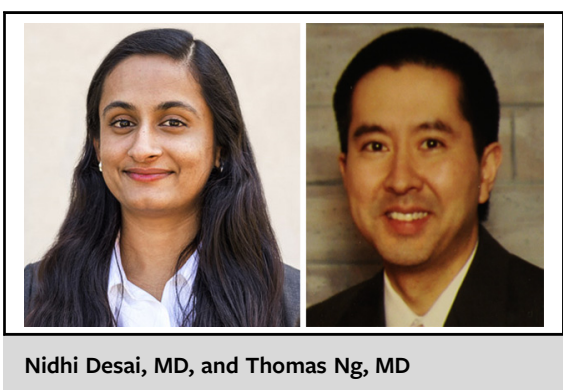

CENTRAL MESSAGE

Recurrence rates after repair of paraesophageal hernia continues to be high. Surgeons should adhere to all components of the repair and perform each with great attention to detail.

do much better; surgeons should honestly evaluate their recurrence rates and, if high, improve their technique. This Video Atlas article by Alicuben and colleagues ${ }^{3}$ provides the perfect start; it is indeed a must-read (mustview) for surgeons of all levels who seek to tackle the repair of such a complex region.

As a final thought, it has been more than a decade since Luketich and colleagues ${ }^{4}$ first published their outstanding results with laparoscopic repair of giant paraesophageal hernia. As the authors have shown, the development of new techniques is of paramount importance toward reducing morbidity for our patients. Hopefully, the authors continue to review and share their results for the more recent cohort to elucidate a promising trend for decreased recurrence rates.

\section{References}

1. Stylopoulos N, Rattner DW. The history of hiatal hernia surgery: from Bowditch to laparoscopy. Ann Surg. 2005;241:185-93.

2. Laliberte AS, Louie BE. Short-term and long-term outcomes of paraesophageal hernia repair. Thorac Surg Clin. 2019;29:405-14.

3. Alicuben ET, Luketich JD, Levy RM. Laparoscopic repair of giant paraesophageal hernia. J Thorac Cardiovasc Surg Tech. 2021;10:497-502.

4. Luketich JD, Nason KS, Christie NA, Pennathur A, Jobe BA, Landreneau RJ, et al. Outcomes after a decade of laparoscopic giant paraesophageal hernia repair. $J$ Thorac Cardiovasc Surg. 2010;139:395-404.

5. Maziak DE, Todd TR, Pearson FG. Massive hiatus hernia: evaluation and surgical management. J Thorac Cardiovasc Surg. 1998;115:53-60. 